Voix et Images

voixetimages

\title{
Montréal imaginaire. Ville et littérature
}

\section{Antoine Sirois}

Volume 19, numéro 1 (55), automne 1993

Lionel Groulx écrivain

URI : https://id.erudit.org/iderudit/201076ar

DOI : https://doi.org/10.7202/201076ar

Aller au sommaire du numéro

Éditeur(s)

Université du Québec à Montréal

ISSN

0318-9201 (imprimé)

1705-933X (numérique)

Découvrir la revue

Citer cet article

Sirois, A. (1993). Montréal imaginaire. Ville et littérature. Voix et Images, 19(1),

179-182. https://doi.org/10.7202/201076ar

Ce document est protégé par la loi sur le droit d'auteur. L'utilisation des services d'Érudit (y compris la reproduction) est assujettie à sa politique d'utilisation que vous pouvez consulter en ligne.

https://apropos.erudit.org/fr/usagers/politique-dutilisation/ 


\section{Montréal imaginaire. Ville et littérature}

Antoine Sirois, Université de Sherbrooke

Montréal hante depuis longtemps l'imaginaire québécois, depuis les récits de fondation aux récits migrants contemporains.

Mais ce n'est que tardivement, avec les années soixante, que les littéraires se sont penchés de façon un peu systématique sur l'expression littéraire de Montréal. Jusqu'aux années quatre-vingt, quelques articles, ceux de Georges-André Vachon ${ }^{1}$ (1966) et de Lise Gauvin (1978) en particulier, un numéro de revue, Liberté ${ }^{2}$ (1963), deux thèses de doctorat à notre connaissance, et soutenues en France, celle d'Antoine Sirois, parue sous le titre de Montréal dans le roman 
canadien (1968), couvrant de 1940 à 1965, et celle de Yannick Resch, L'imaginaire de la ville; Montréal dans la fiction québécoise de 1940 à 1980. Depuis 1980, un intérêt croissant s'est manifesté qui a culminé dans un projet de recherche, étendu sur cinq ans, intitulé Montréal imaginaire $^{3}$, regroupant des étudiants et professeurs du Département d'études françaises de l'Université de Montréal. Il était suscité par le $350^{\mathrm{e}}$ anniversaire de la métropole:

Deux des principaux instigateurs du projet, Gilles Marcotte et Pierre Nepveu, ont pris la direction de la publication du principal ouvrage à émaner de la recherche. Le plan suivi est historique et les auteurs ont dégagé les nœuds où l'imaginaire montréalais semblait offrir "des significations particulièrement riches": les temps de la fondation, le xIX $^{\mathrm{e}}$ siècle, les années trente, 1945 à nos jours, période où la littérature se fait plus urbaine mais aussi plus cosmopolite.

Les directeurs de l'ouvrage affirment sans détour dans leur introduction: «Il est évident que, sans Montréal, la littérature québécoise n'existe pas", à cause de l'importance de l'institution littéraire - mais ils ajoutent: "Peut-on dire que Montréal n'existe pas sans la littérature?. (p. 7). Une ville existe littérairement, selon eux, lorsqu'elle fait question. Si Montréal existait auparavant comme menace, ce n'est qu'aux environs des années soixante qu'elle est "devenue une question ". La littérature reflète l'évolution de la métropole mais pour Marcotte et Nepveu: "La littérature et la ville concrète, habitée au jour le jour, se rencontrent dans une zone intermédiaire qui tient à la fois du fait littéraire et du fait vécu: toute la ville est pour une large part imaginaire $[. .]$.$* (p. 9).$

Ginette Michaud ouvre l'étude par la lecture de quelques récits de fondation. Elle se demande: "Que nous donnent à imaginer les récits de fondation de Montréal, en sa primitive Ville-Marie?» (p. 13). S'ensuit une analyse élaborée des récits depuis Jacques Cartier en passant par Marie Morin, Dollier de Casson, jusqu'à Lionel Groulx. C'est vraiment en littéraire qu'elle étudie les textes historiques où pour elle "la fiction est mêlée dès le départ à l'histoire, le mythe à la réalité, ce qui est imaginé à ce qui est vécu [...]• (p. 88).

Gilles Marcotte nous entraîne dans les mystères de Montréal, tirés de sources autant anglophones que francophones, ce qui apporte une lumière révélatrice à son analyse. Comme il le constate, Montréal intègre déjà au XIX ${ }^{\mathrm{e}}$ quelques-uns des mythes essentiellement troublants de la ville, en relation étroite avec le mythe moderne. Il décèle, il va sans dire, l'influence des Mystères de Paris d'Eugène Sue, alors que trois romans d'ici portent les noms suivants: Les Mystères de Montréal, 
The Mysteries of Montreal. Dans une perspective comparatiste, Marcotte conclut que de l'activité narrative du $\mathrm{xIx}^{e}$ siècle ne pouvait naître un véritable mythe montréalais, parce que n'existent pas

les médiations nécessaires entre la vision clérico-nationale et celle du récit populaire d'une part, entre le Montréal victorien de mesdames Leprohon et Führer et le Montréal francophone d'Auguste Fortier et d'Hector Berthelot d'autre part. Le Montréal littéraire - ou paralittéraire, si l'on veut - qui naît à cette époque est une ville d'individus, une ville qui ne se découvre que par morceaux, par fragments, refusant de se laisser saisir par la vue d'ensemble. Mais, dans son désordre, ses vulgarités, ses naïvetés, il est terriblement vivant. Et il énonce les conditions d'une expérience urbaine qui est encore, en grande partie, la nôtre (p. 147-148).

Michel Biron, pour sa part, s'intéresse au tournant du siècle à Montréal, dans la poésie et le roman. Malgré le vent de libéralisme qui souffle sur la métropole et encourage la course au progrès et en dépit de l'événement majeur que constitue la création de l'École littéraire de Montréal qui projette de se soustraire aux prérogatives cléricales et politiques, la conquête de la ville s'effectue péniblement.

Règle générale, il semble difficile de ne pas se défaire à Montréal: Robert Lozé, Jules Faubert, le père Beaulieu et Paul Mirot goûtent tour à tour au pouvoir de la ville et n'y répondent que par des échappatoires qui laissent intact ce pouvoir. Toute riposte semble exclue d'avance, comme si l'on ne pouvait que subir Montréal. Tous reconnaissent la justesse des ambitions générées par l'esprit d'entreprise, par l'honnête spéculation et par la loi du marché, mais leur appréciation favorable de la ville semble paradoxalement les rendre plus vulnérables (p. 209).

C'est au Montréal dans la prose narrative, aux abords du * grand tournant . de 1934-1936, que nous convie Pierre Popovic. Un Montréal pas encore très heureux, marqué par le chômage, que l'on hésite du reste à nommer. Comme conclut l'auteur: "Les proses narratives montréalaises renforcent et confortent le sociogramme montréalais des années trente. Elles y insistent: la seule façon d'habiter Montréal est de la quitter " (p. 269). L'importance accordée dans cet article à Marie Le Franc surprend un peu. Ne devait-elle pas être retenue comme un regard "autre" par rapport à la tradition imaginaire québécoise, touchant la ville, que présente l'article?

Jean-François Chassay intitule à juste titre son article "L'autre ville américaine •. Si, comme il le souligne, la présence américaine est peu explicite entre 1940 et 1970 dans le roman de Montréal, il n'en reste pas moins qu'il y a tout un mouvement qui impose une ville très concrète, décrite d'abord et avant tout à l'image de la grande ville américaine. Pensons au Poids du jour, à Alexandre Cbenevert, au Nez qui voque. 
On regrette l'absence dans cet article, ou dans un autre qui y serait consacré, de l'importante contribution du roman anglophone depuis 1945 à l'imaginaire de Montréal, dont, sauf erreur, le projet de recherche s'est aussi préoccupé. Relevons d'abord des auteurs comme Hugh Maclennan avec Two Solitudes (1945) et en particulier The Watch that Ends the Night (1959), un des romans les plus évocateurs écrits sur Montréal, et les œuvres de Mordecai Richler qui traduisent l'important regard canadien-juif sur la métropole. Ajoutons aussi Leonard Cohen et Mavis Gallant parmi d'autres.

Pierre Nepveu expose les différents angles de vision en poésie pour une ville, convoquant les productions canadienne-française, canadienne-anglaise et canadienne-juive qui construisent respectivement une image de Montréal qui leur est propre. Nepveu relève l'abondance des poèmes écrits en français et en anglais depuis 1945. Il ajoute: "Nous sommes devant une "forêt de symboles", une multiplicité de symboles et de thématiques* (p. 335). Il procédera donc avec beaucoup de perspicacité et de nuances dans ses comparaisons.

Un dernier article fort pertinent de Simon Harel: «La parole orpheline de l'écrivain migrant ", dont la perspective d'analyse est influencée, selon l'auteur, par *l'importance d'une problématique cosmopolite qui définit la dimension contemporaine de la littérature québécoise ( Étienne, Régine Robin, Antonio d'Alfonso et soulève les thématiques de l'exil, de la marginalité, de la constitution de l'identité.

Voilà, somme toute, un ensemble riche et fécond qui couronne une recherche longuement poursuivie, mais qui ne la clôt pas. La transition, surtout manifeste depuis les années quatre-vingt, de Montréal qui de mère dévorante devient mère bienveillante, sera encore à souligner dans les romans d'Yves Beauchemin, de Francine Noël, de Michel Michaud, de Christian Mistral. Ce dernier voit explicitement en Montréal une "mère chaude et rassurante". L'abondante documentation accumulée pourra permettre d'enrichir et de compléter le Montréal imaginaire.

1. Lise Gauvin, aUne ville en mode mineur: considérations sur Montréal dans le roman récent , Possibles, vol. III, n' 1 , automne 1978, p. 11-23.

2. Georges-André Vachon, a L'espace politique et social dans le roman québécois., Recherches sociographiques, vol. VII, $\mathrm{n}^{\circ} 3,1966$, p. 259-279.

3. Gilles Marcotte et Pierre Nepveu (directeurs), Montréal imaginaire. Ville et littérature, Montréal, Fides, 426 p. 